Journal of Social Sciences 7 (2): 274-279, 2011

ISSN 1549-3652

(C) 2010 Science Publications

\title{
Community Participation Tourism Management Model of Tapee Plain Community
}

\author{
Wansart Srisuwan, Songkoon Chantachan and Pairat Thidpad \\ The Research Institute of North Eastern Arts and Culture, \\ Mahasarakham University, Maha Sarakham, 44000, Thailand
}

\begin{abstract}
Problem statement: Cultural tourism plays an important role in the economy system of Thailand. This study, therefore, aims to investigate the following: (1) The tourism conditions in the community of Taa-Pee River Basin and also; (2) The possible guideline of organizing the cultural tourism, by all means, seeking active cooperation among the Taa-Pee River Basin community people who subsist or have been subject to the river basin and the surrounding conditions. Approach: This research was conducted in Surat-Thani Province. The sample consisted of 370 subjects obtained by Specified Random Sampling. The instruments used in data collection included the interview form and the observation forms constructed by the researcher. The data were also gathered by means of the Focus Group Discussion and the Participatory Workshop. The data obtained were then examined by the Qualitative Analysis. Then, the examined data were presented in Descriptive Analysis. Results: The results obtained and examined indicated the following: (1) The Taa-Pee River Basin community had long been the international trade/commercial center into which the transactions between the Arabian nations and China had entered into from the time before the seventh B.E. Most of the community people were of Sino-Thai, Semang and Malayan. They earned their living by doing agricultural farms or fishery. The community had their own outstanding unique, typical identity, advantageous for tourism. (2) The important problems of tourism management included the following: the tourist attractions were not fascinatingly attractive; There were few tourism activities; The tourism attractions were scarcely pioneered, renovated, improved and developed; Lack of exact personnel in charge who could be consecutively on duty; Lack the central sector to do the work related to management and providing massive wholeheartedly support. In brief, such deficiency accounted for the imperfect tourism management. (3) The form of managing cultural tourism focusing on/providing the Taa-Pee River Basin community people with a great extent of full participation. The actual/significant elements of managing the community's participation-based cultural tourism. The focal factors of management included vision, mission, strategy, tour activities, objectives/goals and the conditions of achievement which accounted for tourism being managed to meet the tourists' needs on the principal basis of maintaining and keeping up with the natural resources and environment. The crucial point to be aware of was the strong determination to further inherit/pass on the Taa-Pee River Basin's folks' wisdom and ways of living Consequently, every part/person in the community was required to share a cooperative task. Conclusion: As part of the encouragement of cultural tourism there should be a proctoring measure to help control, look after and supervise the tourism resources and as well partially share all of its benefits. Last but not least, precisely determine to keep up with their sustainable advantages.
\end{abstract}

Key words: Community participation, tourism management model, Tapee plain community, cultural tourism, qualitative analysis

\section{INTRODUCTION}

The Taa-Pee River was the route used as the bypass of traveling from the Andaman Sea out to the Gulf of Thailand. This characteristic natural feature accounted for the Taa-Pee River Basin's community people's ways of living. Particularly, in certain area of the Baan-Daun Gulf had long been the town which interacted the sea-trade between the Arabian countries and China. This existed prior to the seventh BE.

Corresponding Author:Wansart Srisuwan, The Research Institute of North Eastern Arts and Culture,

Mahasarakham University, Maha Sarakham, 44000, Thailand Tel: +66-43-721686 


\section{J. Social Sci., 7 (2): 274-279, 2011}

According to the geographical chronicle recorded by Quadius Ptolemi (AD 150), he also gave an assumption that there was a piece of evidence affirming from a sign left indicating that there used to be a route starting from the Gulf of Thailand to enter into the Taa-Pee River Basin. Furthermore, this route could also be taken as the exit for the Mean Canal, the Oak Canal, the WangHeep Canal and the Trang River. By this route it was possible to travel further to the exit toward the Andaman.

Sea which had been used until the tenth B.E. After that, this route was completely closed due to the long time passing by and parts of the canals naturally happened to become shallow. In his chronicle Quadius also mentioned about the Pun-Pin City situated in the seventh B.E. in the vicinity of the Gulf of Baan Daun. Approximately in the twelfth century, there existed the Sri-Wichai Domain having the Chaiya as its powerful collateral region acting as an emporium in which spice was the most popular commodity goods put for sale.

The Sri-Wichai Domain had been expanded and it was necessary to rightfully exercise its control over Malaysia and Indonesia.

In the thirteenth B.E. They attacked the Cham-Pa Town of Cambodia and in the fourteenth B.E. they expanded and extensively exerted their power to govern the Jora region and occupied the Lanka island. However, from the sixteenth BE until the sixteenth B.E. the King of Indonesia Kingdom carried out a counter attack on Sri- Wichai domain and the "Tam PaRa-Link” or the present Nakhon-Sri- Thammarat. These several consecutive attacks affected Sri-Wichai Domain to such a great extent of weaknesses.

Until 2Ist-22nd BE Portugal and Netherlands/Halland entered into Thailand aiming to establish their trade stations in the Cape of Ma-La-Yu. Simultaneously, China promoted their trading policy by opening direct trading business transactions with many other countries. Inevitably, such movements exerted enormous impacts on Sri-Wichai's former outstanding roles. In other words, their glorious days have been diminished.

According to the chronicle, several people in those days casually remarked on prosperous and sustainable establishment of Buddhism during the Sri-Wichai Domain. Apparently, there were thousands of Buddhist monks Among them, one of the Buddhists, whose religious name was Bhikhu/Phra "Ee" made a pointed remark to urge the thousand Chinese monks who planned to leave for India with strong belief and determination that they would be better inculcated and would acquire Buddhist principles more in depth. Instead, he recommended that they take such whole time of hard effort to become fluent and proficient in Sanskrit. Fundamentally, deeply religious persons would dedicate their time earnestly/fully to comprehend most of the Lord Buddha's teaching of ultimate truth/doctrine and, best of all, axiomatic precepts. In fact, these Chinese monks were supposed to spend merely 1-2 years participating in this extra-intensive training session. Besides, the Sri-Wichai Domain had the exclusive proto-typical valuable artworks in their possession. Sri-Wichai Domain, therefore, had got the pseudonym " the Home of Craftsmanship. Actually, the domain was exquisitely embroidered with intricate, magnificent intellectual property were apparently reflected in/portrayed by its ancient remains and antiques which have been inherited and highlighted the priceless and rare property/possessions. A body of concrete evidence emerged suggesting that some of the ancient remains and antiques had become the concrete evidence to prove that they had existed not less than a thousand years. In the reign of King Rama IV (Phra Chaum Klao, His Majesty was graciously pleased to let the Taa-Taung Town be moved and be reestablished at Baan-Daun, the present Town with the same old name. Later, He royally promoted it to be the fourth-graded town subject direct to the Bangkok Metropolis and He was pleased to let it be more commonly known by the name "Kan-Cha-Na-Dit" town. However, in the reign of King Rama V (King Chulla Chaum Klao) He was graciously pleased to reorganize Thailand's official systems including the employment of Provinces. The reformation resulted in the conglomeration of the ChaiYa Kan Cha Na Dit town, Lang-Suan District and Chum Paun/Porn District into the Chum Porn Province in 1898. Later on, in the reign of King Rama VI (King Mong-Kut) this name was graciously pleased to be renamed "Surat Thani” town. Simultaneously, He was pleased to rename the Luang River into the Taa-Pee River.

As aforementioned, the Taa-Pee River community was full of great diversity and abundance of natural resources. In addition, it was provided with enormous cultural heritages that served as its adequately high social cost. These have been the good reasons why a plethora of enthusiastic visitors planned to tour all over the community. The longer the time passed by, the greater number they came. It was a pity that the community had no idea of how to process the data of tourists advent figures; neither could they figure out the profitable income they could earn. One of the important matters they should have dealt with was to know if there were any impacts on the tourists' widespread dissatisfaction. As it was proved conclusively, a fundamental defect in tourism management on account of the fact that a few number of community people had 
their active participatory role in the tourism management. Despite the fact that these people had got full potential at least as junior managers, the efficient management staff was still urgently needed.

In particular, one of the solutions to the problem of community personnel's playing the least part in tourism management. Was that the management had better be manipulated and supervised in the form of committee. This sort of action could be taken by the community organization.

The community's current problems have inspired the researcher to investigate on "The Forms of Cultural Tourism Management with Dependence on the fully Active Participation of the Community People in the Vicinity of the Taa-Pee River Basin”. The delimitation of this study was that the community people played their parts in determining the tourism management forms more likely to result in the success of tourism management to the considerable extent of satisfaction which resulted from the community's initiation.

More or less, the administrative burdens, related either to tourism management or allocation of profits gained for those concerned or rightly deserved, would be alleviated. Profoundly, the accumulative profits would be put away or deposited for the future use related to large- scale tour operation including the provision of all sorts of convenience and facilities for tourists and for the maintenance of the community's cultural heritages.

\section{MATERIALS AND METHODS}

The areas used in this investigation included SriWichai Sub-district, Lee-let Sub-district, Pun-Pin District, Surat-Thani Province. Also included were Bang-Po sub-district, Bang-Bai-Mai sub-district, Muang Surat Thani District, Surat-Thani Province.

This was a Qualitative research. The sample consisted of the 90 well-versed or persons in-the-know, $120 \mathrm{principal} / \mathrm{main}$ data providers, 160 community folks in general. These groups of population accounted for the total of 370 subjects.

The instrument used for data gathering were the interview form, the observation form, the Focus Group Discussion and the Participatory Workshop; the data obtained were then examined by the Triangular Technique based on the issues previously determined for investigation. The results were discretely presented in descriptive analysis.

\section{RESULTS}

The findings revealed the following:
- The Community of Taa-Pee River Basin particularly in the vicinity of the Baan Daun Gulf, Surat Thani Province. had been used as the seatrade emporium for the dual enterprisers between the Arabian countries and China for such a long time from the time before the seventh B.E.: It was an area occupied by the Sri-Wichai Domain. The majority of people descended from the Sino-Thai lineage including also those of Semang and Malayan lineage; Most of them pursued successful career in agriculture and fishery dependently upon the physical features of the land they dwelled on; in this case they were on the low land topography. However, they had their own distinctive cultural identity in favor of tourism as in languages, literary works, folk plays and dramatics, religious rituals and beliefs, customs, festivals, cultures and wisdom, ancient remains and antiques as well as the river basin's nature/condition of ecology movement depicting outstanding unique identity

- The main problems of the Taa-Pee River Basin's cultural tourism management lay in the following defects: the tourist attractions were unattractive; few and not varied activities were organized; the existed attractions that required rehabilitation, renovation, development and pioneer were largely ignored; there was not any directly/potentially liable host to be seriously and lengthily duty bound; neither was there any service center successfully managing and generously supporting the business; the sub-district administrative organization in the target areas gave little interest in and made a minor contribution to the tourism development; no ambitious plan nor project relevant to the development of tourism management; the community people's cooperation and participation were desperately needed including those of other organizations' in the operating area; seeking a full understanding and thorough/sufficient public relations relevant to the conservation and development of tourist attractions including the development of tourism were also in really need and the urgent actions to be taken; there must be the important guideline of cultural tourism focusing on the Taa-Pee River Basin's community, what's more, there must be main hosts competently managing tourism; there must be the feasible plan for the community's tourism management which had to put the emphasis on the community's participation and it would be more likely in terms of practicality if it was part of the community's plan; they were obliged to develop the firmly fundamental structure as well as the considerable 
potential of the tourist attractions based primarily on creating their stunning attractiveness; It was much more important to enhance the uppermost capability of accommodating and facilitating the tourists and in terms of the development of management it was essential to obtain profound knowledge and to reflect true understanding of the cultural heritages; it was also essential to conserve, develop and build up the added value from tourism; On the other hand, the tourism activities were to be varied and it was significant to come to the realization that the tourism was based its management on the topic of conservation; The business-like management to be dealt with by every sector/agency of which all personnel were supposed to share their parts, as in brain storming, cooperative planning and performance and helping with the project assessment/evaluation and last but not least expressing the sense of approval/satisfaction in the advantages or profits mutually gained from the strongly exerted effort in achieving the established goals

- The form of cultural tourism organization with an emphasis on the Taa-Pee River Basin's community people's active participation. Actually, it was a methodological form, which was the scope of methods employed in the management of tourism through the following composite factors: vision, mission, strategy, tourism activities; including the goals as well as the stipulation of achievement. In short, it was a tourism management with the emphasis on how to meet the tourists' needs on the basis of conservation of natural resourcs and environment as well as the inheritance of folks' wisdom together with the Taa-Pee River Basin community people's ways of living. To urge those involved to raise the people's full consciousness of giving to some extent contribution to the conservation of some precious resources and perceiving the huge advantages of cultural tourism. Furthermore, in order to implement the plan urged the people to spend available time looking into the tourists' fundamental requirements. Now, it's high time the people be provided for their parts to play in managing the tourism; let them be possessive of (and gain some advantages from) the community cultures; the committee put forward broad recommendations for the consecutive development of tourism management and they had also produced a set of recommendations for managing integrated tourism to the full/complete cycle of planning, operation, evaluation and improvement for development; in terms of tourism management, it was suggested that the tourism activities be highly varied and be strictly organized under established regulations which could be further firmly held as the practical framework for the programs to be managed fruitfully in collaboration

\section{DISCUSSION}

The research findings could be discussed as follows:

- The cultures for the benefit of cultural tourism organized by the Taa-Pee River Basin community: the historical background of the community was extraordinarily interesting; the remaining traces were reliable and distinct indicators of their ethnics, their settlement in the past made a positive contribution to tourism management from which the tourists could derive and acquire the knowledge of history and cultures; that is to say, what they heard about and caught sight of was not only something they had planned for the tour, but they were also offered first-hand experiences; As a matter of fact, they had got good/big chances to mix/associate with community people in their reallife settings. Best of all, they could even get close to and admire the arts and cultures of those countries. The cultural tourists had a great interest in cultures. Therefore, this new sort of tourism adopting cultures to enhance the added value was to some extent in conformity to the ideas presented in Chirawatanasate (2001) study: the folks' media with their status as the cultural capital for tourism encouragement in the form of 'cultural stay'. The results of the study indicated that the "cultural stay" or the "home stay" was an alternative of tourism in Thailand. This new pioneer resulted in Thailand's having new advent of service sales business to be presented to both domestic and overseas tourists. This business was highly beneficial for folks, that is, they could possibly apply their knowledge and intelligence to manage tourism in their locality. Actually, the cultural stay or homestay tourism was appropriate for tourists who wanted to acquire/learn and exchange for cultures, customs and local ways of living

- As for the local ways of living, the results revealed that the people in the community of Taa-Pee Rivr Basin had interesting ways of living since their ways of living were of typical identity. With respect to language, literary works, the folks plays, religions, beliefs, customs, festivals and occupations. These aspects seemed to be helpful for organizing activities for tourists to come and 
see the cultural activities which were quite different from other communities. Those were the reasons why tourists wanted to come and see the community of Taa-Pee River Basin. The other reason was that the people in this community would never damage the natural resources, environment and culture. These reasons were in conformity to Fenmel (1999) idea. He thought that tourism had to keep away from harming environment. Tourism had to work in collaboration with the local communities campaigning against harming culture and natural resources. Tourism had to hold the highest regard to all local cultures. Dealing with tourism activities, they had to bear in mind and reminded themselves of avoiding aggressive behaviors probably leading to ruining or depreciating the value of culture. The tourism organization was supposed to be prepared and forced to concede that merely the local people gained most of the profits earned. Tourists, on the other hand, derived great satisfaction from such an expressive tourism management

- With respect to cultural tourism management, the results revealed that the guideline of tourism managed by the active participation of the majority of community people together with various sectors' joint efforts. Dependence upon such conglomeration, the operation towards the ultimate goals; that is to say, a solid achievement could possibly be constituted, or they all would be given a prize for their great dedication and determination to accomplish the targeted enterprise. Apparently, such success would conform to The World Health Organization's ideas. Similarly, (Sucharitchit, 1996) not only did her study reveal similar findings most of which threw her full support to the ideas above. She raised a magnificent sum to delightfully illustrate the exactly practical scheme of encouraging increased participation in the management process: the simple three-step procedure consisted of: planning, being involved in undertaking activities, making an exceptionally useful contribution to the enterprise and making full use of the obtainable profits being properly proportioned

- The form of organizing cultural tourism with the emphasis on the active participation of the Taa-Pee River Basin community people including also those from the eight sub-district participants. Obviously, the form of activities employed and the programs/itinerary for the tours in details were quite similar; due to the fact that they all were the community people dwelling in the vicinity of the same river basin. Moreover, the aims of employing tourism as the tool for telling the stories of their own community to tourists. Consequently, the guidelines were issued in the form of network with clear structures of task performances. Their liabilities and roles were allotted in order that the burdens could be properly distributed. Their profits, on the other hand could be also distributed as an overall image. They performed their tasks in line with determined agreement and regulations. What's more, they shared their management approach in common; thus, all decisions were made with reference to the meeting's and every member's resolutions. In conclusion, everyone had their fundamental freedom of thought; that is to say, they had got standard procedures for mutual exchange of knowledge, In turn, there were exchanges of conformably proper and feasible schemes that could possibly result in really concrete advantages; these guidelines were entirely consistent across Watana-Pooti (1995) investigation on "Social Opinions on Cultural Relativity”. He specifically referred to an analysis of social relations as if it were merely to discriminate and to give an explanation about "how do various groups of people in society relate to one another?" and "What sorts or patterns of relations are there?". Another question is "In what certain context does each pattern take place?" Therefore, the analyses of social relations are commonly referred to as "Education”, “Social Organization”, “The Intramural relations among Organizations/Groups" and "The Sub-Cultures among Particular Groups"

\section{CONCLUSION}

The results of this study were so significant that both the government sectors and the private ones were obliged to really appreciate the true significance of the research findings of which some implications could be applied to the improvement and promotion of cultural tourism; the prompt action to be taken was to form the main committee and then one with suitable qualifications was elected and appointed to assume the liability as the chair of the committee urgently starting with planning, public relations, seeking all sorts of support and encouragement, asking someone to do the follow-up task; when defects and faults were uncovered, the improvement and development stages could be certainly and consecutively taken on. To sum up, such a well-planned and well-equipped strategy 
would assure the community and those involved of successful tourism management in the long run.

\section{ACKNOWLEDGEMENT}

The researcher would like to thank his advisor 4th advice, Office of Higher Education, Research Institute of Isan Art and Culture, Mahasarakham University for providing Research Grant, the key informants and very one of related persons for supporting this study until it was completely finished.

\section{REFERENCES}

Watana-Pooti, C., 1995.The Stage of the Host of the Tours. The Institute of Society Research. Chiang Mai University, Chiangmai, ISBN: 974-565-835-9, pp: 165-174.
Sucharitchit, M., 1996. Christians and their participation in the conservation of environment: A case study of Christians under the supervision of the church of Christ in Thailand, Bangkok Metropolis. Master Thesis, University of Business Graduate, pp: 183-184. ISBN: 974-640-020-7

Chirawatanasate, W., 2001. Folks' media with the implementation of culture to promote the launch of new alternatives of tourism "The cultural accommodation" or the former popular name as "the home stay": The case study of Baan Pra Sart, Nakhon Ratcha Sima. Master Thesis, University of Business Graduate, pp: 201-203. ISBN: 974-281672-7

Fenmel, D.A., 1999. Ecotourism: An Introduction. Routledge, New York, ISBN: 0-85199-609-4, pp: 31-33. 